\title{
SHORT-TERM EFFECTS OF A SINGLE DOSE OF GONADO- TROPHIN RELEASING HORMONE (GnRH) VACCINE ON TES- TICULAR AND EJACULATE CHARACTERISTICS OF DOGS
}

\author{
T. A. AJADI ${ }^{1} \&$ M. O. OYEYEMI ${ }^{2}$ \\ ${ }^{1}$ Department of Veterinary Public Health and Reproduction, Federal University \\ of Agriculture, Abeokuta, Ogun State, Nigeria; ${ }^{2}$ Department of Veterinary \\ Surgery and Reproduction, University of Ibadan, Ibadan, Nigeria
}

\section{Summary}

Ajadi, T. A. \& M. O. Oyeyemi, 2015. Short-term effects of a single dose of gonadotrophin releasing hormone $(\mathrm{GnRH})$ vaccine on testicular and ejaculate characteristics of dogs. Bulg. J. Vet. Med., 18, No 2, 123-131.

The short-term effect of gonadotrophin releasing hormone ( $\mathrm{GnRH})$ vaccine was evaluated in ten adult male dogs with mean weight of $8.0 \pm 1.2 \mathrm{~kg}$, and age ranging between 1 and 3 years. The first group (control) comprised five intact dogs treated with normal saline, while the second group included five dogs treated with a single subcutaneous injection of $400 \mu \mathrm{g} \mathrm{GnRH}$ vaccine. Semen was obtained from the dogs before the administration of the vaccine and thereafter fortnightly up to twelve weeks for determination of semen volume, sperm concentration, motility, percentage live-dead ratio and abnormal spermatozoa percentage. Also, the scrotal circumference of the dogs was measured fortnightly for sixteen weeks. At the end of the $16^{\text {th }}$ week, testis of the control and treated dogs were surgically removed, the short and long axis determined, and fixed in Bouin's fluid for histopathological examination. The testicular dimension, sperm volume, percentage sperm motility and sperm concentration were presented as mean $\pm \mathrm{SD}$ and compared using repeated measures ANOVA (SPSS 17.0 software). The scrotal circumference was significantly $(\mathrm{P}<0.05)$ lower in the treated dogs than in controls. The testicular dimension of control dogs $(6.1 \pm 0.7 \mathrm{~cm})$ was significantly $(\mathrm{P}<0.05)$ bigger than that of treated dogs $(4.4 \pm 0.3 \mathrm{~cm})$ Histologically, the testes of treated dogs showed clear disruption both in the number and morphology of the interstitial Leydig cells. The mean semen volume, sperm motility, concentration and live-dead ratio decreased $(\mathrm{P}<0.05)$ two weeks after treatment in vaccinated dogs, and thereafter the dogs became aspermic. It was concluded that the single injection of $\mathrm{GnRH}$ vaccine produced changes in the testes and semen of dogs and infertility up to post vaccination week 16.

Key words: dogs, immunocastration, GnRH vaccine, semen, testis

\section{INTRODUCTION}

Pet overpopulation is a serious problem that often results in animal abandonment and relinquishment. It places strain on animal shelters and shelter personnel, and 
leads to euthanasia of unwanted pets (Bartlett et al., 2005; McNeil \& Constandy, 2006). Castration is a major method of controlling dog populations. In addition, there are behavioural and other health benefits from castrating dogs as opposed to leaving them sexually intact. These include decreased urine spraying in male cats and decreased incidence of certain neoplasms of the reproductive organ (testicular and prostatic tumors) in male dogs and cats (Kustritz, 2007).

Surgical castration is the traditional method of gonadectomy in male dogs and cats. However, welfare concerns regarding surgical method of castration in most domestic animals have recently emerged, due to surgery pain, the risk from complications after general anaesthesia. Also, the surgical removal of the testes is considered unnatural and objectionable. For instance, a recent study conducted in Brazil showed that the main reasons for the avoidance of surgical castration of adopted shelter dogs included compassion $(56.5 \%)$, while $11.4 \%$ of the respondents considered the procedure as unnecessary (Soto et al., 2005). Serious complications such as infections, scrotal abscesses, rupture of the surgical wound, and chewed out sutures were reported following surgical castration in dogs (Lund et al., 2006).

The growing concerns about surgical castration have necessitated the development of alternative methods of castration which would be effective and acceptable to the animal owners in terms of welfare. Zinc gluconate as a chemical castration agent, approved for use as a non-surgical alternative to bilateral orchiectomy in male dogs at 3 to 10 months of age with testes measuring 10 to $27 \mathrm{~mm}$ in width. This zinc compound, which is neutralised by arginine, is delivered by intratesticular injection, resulting in sclerosis of the tes- tes and permanent sterility (Oliveria et al., 2007). The advantages of zinc gluconate as an agent for castration include low cost, ease of use, and cultural acceptance. It may be a valuable option for large-scale use in dogs, particularly in remote locations lacking sophisticated clinical facilities or skilled surgeons and staff (Levy et al., 2008). Local adverse reactions including scrotal necrotising ulcers and development of draining tracts have been documented (LaCroix, 2006). Zinc gluconate treatment in dogs have resulted in a considerable individual variation in testicular size with some animals showing no change after treatment and others showing small and fibrotic testes (Levy et al., 2008). The other disadvantage is that intratesticular administration of the agent requires certification.

Potent GnRH-agonists have also been approved for male dog contraception in New Zealand and Australia. GnRH agonists such as deslorelin have been shown to suppress gonadal activity in both male and female dogs with few side effects. The drug acts by causing a down-regulation of the GnRH receptor, resulting in chronic suppression of LH and FSH concentrations (Wiebe \& Howard, 2009). This will in turn cause suppression of gonadal hormone secretion and gametogenesis leading to chemical castration. However, these agents are not readily available and are too expensive to make their use in veterinary practice routine especially in the low income countries.

Immunocastration is an immunological castration method which is currently undergoing evaluation for its efficacy and adverse effects. Immunocastration works as a vaccine, stimulating the immune system to produce antibodies against the gonadotropin-releasing hormone $(\mathrm{GnRH})$ (Thompson, 2000). The antibody neutra- 
lises endogenous GnRH resulting in suppression of secretion of luteinizing hormone (LH) and follicle stimulating hormones (FSH) (Walker et al., 2007). This will result in testosterone deprivation and subsequent impairment of spermatogenesis. Vaccines against GnRH also have the advantage of suppressing sexual behaviour in males and females (Kutzler \& Wood, 2006). The main concern with immunocastration is the unquantified side effects, achieving efficacy over long periods of time following single injection. The immunotherapy with canine gonadotrophin releasing factor (Pfizer Animal Health) has to be repeated every six months in order to maintain sterility in the dogs (Wiebe \& Howard, 2009).

The aim of this study is to evaluate the short-term effects of a single injection of GnRH vaccine on gross and histopathological testicular morphology and ejaculate characteristics of male dogs to assess the efficacy of the vaccine.

\section{MATERIALS AND METHODS}

\section{Animals}

Ten adult male mongrel dogs (mean weight of $8.0 \pm 1.2 \mathrm{~kg} ; 1-3$ years of age: mean $2.1 \pm 0.3$ years) were used. They were obtained from households who used them either for security or hunting. The dogs were housed individually in concrete-floored kennels and allowed moderate exercise three hours daily. They were fed once daily on Indomie waste, supplemented with sufficient amount of proteins (fish) and palm oil, while water was provided ad libitum. They were dewormed with subcutaneous injection of $10 \%$ Levamisole hydrochloride at the dose of 10 $\mathrm{mg} / \mathrm{kg}$, while external parasites were treated by dipping in Diazintol solution (Animal Care, Nigeria). In addition, the dogs were treated against blood protozoan parasites with intravenous injection of 5\% oxytetracycline (Oxytet ${ }^{\circledR}$, Topsurf, Vancouver, Canada) at $10 \mathrm{mg} / \mathrm{kg}$ for five days. The dogs were trained for eight weeks to get them accustomed to semen collection by masturbation and their semen was analysed to ensure that they were fertile prior to the commencement of study. Also, the dogs were certified to be clinically healthy based on results of physical examinations, complete blood counts and faecal examinations before the study. Ethical approval for this study was obtained from the Research Ethics Committee, College of Veterinary Medicine, Federal University of Agriculture, Abeokuta, Ogun State, Nigeria.

\section{Experimental design}

This controlled, randomised, blinded study involved two groups: the first (control) comprised five intact male dogs treated with normal saline, while the second group comprised five intact male dogs treated with a single subcutaneous injection of $400 \mu \mathrm{g}$ Improvac (Pfizer laboratories Pty, Sandton, South Africa).

The dogs were weighed using puppy type weighing scale before the commencement of the study. Semen was obtained from the dogs before castration and thereafter fortnightly up to twelve weeks of castration using masturbation method. Also, the scrotal circumference of the control dogs and dogs castrated immunologically were determined fortnightly up to sixteen weeks. At the end of the $16^{\text {th }}$ week, testes of control and treated dogs were surgically removed, and the short and long axis were measured.

\section{Measurements}

Both the volume and the colour of the first and second fractions of the ejaculate were 
determined. Thereafter the sperm motility, concentration, morphology and abnormalities were then determined. Sperm motility was assessed immediately after collection. A drop of semen was placed on a slide and examined at $100 \times$ magnification using light microscope. Both the total motility (\% of spermatozoa that are moving) and progressive motility (\% of spermatozoa that are moving in a straight line) were determined. The concentration of spermatozoa was measured on the collected ejaculate containing $\mathrm{F} 1$ and F2 fractions. The WBC Unopette system (Becton Dickinson, Rutherford NJ) was used. Semen was drawn up into the 20 microliter pipette and dispensed into $2 \mathrm{~mL}$ diluent container according to kit instructions. The solution was then discharged into both chambers of the haemocytometer. The number of spermatozoa in the central $1 \mathrm{~mm}$ square (the square that fills the field using the $10 \times$ objective) was then counted. Sperm morphology was assessed by staining the semen sample with Giemsa stain (DiffQuik, Baxter Healthcare, Miami FL) and observing the cells under 1000× magnification (oil immersion). The spermatozoa appeared purple on a clear background. Under oil immersion, 100 spermatozoa were examined and counted. The percentage morphologically normal spermatozoa was their number per 100 spermatozoa. Total normal for the sample was calculated by multiplying total number of spermatozoa in the ejaculate by percentage morphologically normal ones. Also, the stained slide was examined for sperm abnormality. Abnormal spermatozoa were classified as primary defects (those that occur during spermatogenesis, including defects in head shape, bent midpiece, persistent proximal cytoplasmic droplet, and doubling of any portion of the spermatozoon) or secondary defects (those that occur during epididymal maturation or slide preparation, including detached heads, persistent distal cytoplasmic droplets, and bent tails).

\section{Histopathological examination}

Dissected testes were placed into Bouin's solution for fixation. The testes were then trimmed and embedded in paraffin. Five $\mu \mathrm{m}$ sections were cut and stained with haematoxylin and eosin (H\&E) for evaluation with light microscopy.

\section{Statistical analysis}

Data were presented as mean \pm standard deviation. The testicular long axis dimension, sperm volume, percentage sperm motility and sperm concentration were compared between the different groups using analysis of variance (ANOVA) for repeated measures. Least square difference was used for post hoc analysis. All statistical analyses were performed using SPSS 17.0 software

\section{RESULTS}

The scrotal circumference of the control and treated dogs (Fig. 1) increased progressively in control dogs throughout the 16 weeks of observation. Conversely, the scrotal circumference decreased gradually in treated dogs up to the $16^{\text {th }}$ week after castration. The scrotal circumference was significantly $(\mathrm{P}<0.05)$ lower in the treated dogs than the control dogs from week 10 to week 16 .

The testes of the treated dogs were smaller and appeared softer when compared with those of controls. The long axis dimension of the testis of control dogs $(6.1 \pm 0.7 \mathrm{~cm})$ was significantly $(\mathrm{P}<0.05)$ longer than that of the immunocastrated dogs $(4.4 \pm 0.3 \mathrm{~cm})$. 


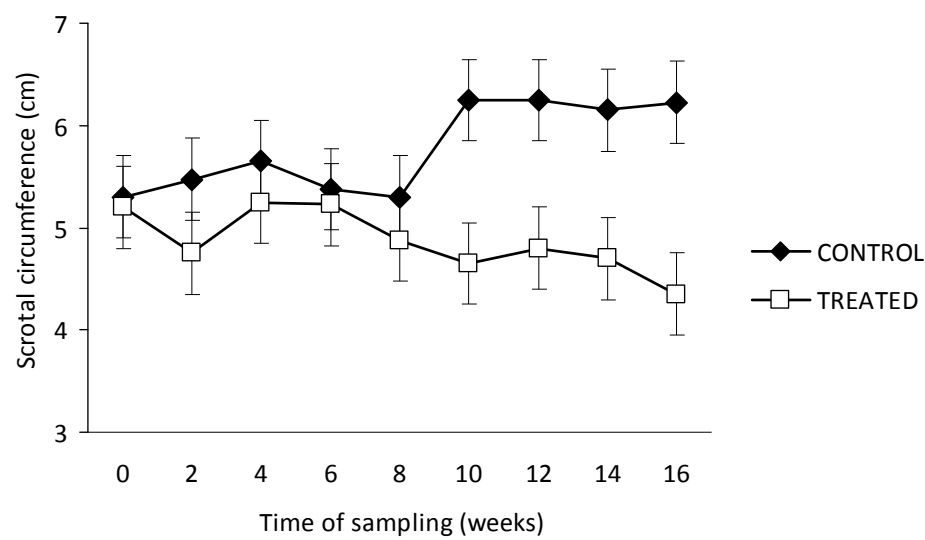

Fig. 1. Comparison of scrotal circumference of $\operatorname{dogs}(m e a n \pm S D)$ following treatment with single subcutaneous injection of GnRH vaccine (treated group; $n=5$ ) or normal saline (control group; $n=5$ )



Fig. 2. Histopathology photomicrograph in a control dog testis showing normal architecture of the seminiferous tubules. H\&E, bar $=100 \mu \mathrm{m}$.

Histologically, the testes of the control dogs showed mostly normal appearance in relation to presence, size and distribution of typical eosinophilic Leydig cells as well as seminiferous tubules (Fig. 2). Spermatogenesis was fully developed in all controls dogs. Testicular histology was clearly affected in treated dogs. Compared with controls, the tubular diameter of the seminiferous tubule was reduced with an apparent reduction in the size of the inter- stitium. There was a clear disruption in both the number and morphology of the interstitial Leydig cells in treated dogs (Fig. 3). The Leydig cells lost their cytoplasmic eosinophilia, were fewer, and were represented by pyknotic-like nuclei, hardly distinguished from the interstitial fibroblasts and endothelial cells. Spermatogenesis was also clearly affected and was characterised by spermatocyte loss and decrease in the normal number of 
layers of germ cells to severe germ cells loss.

The mean semen volume (volume of the first and second fraction) of the dogs ranged between $0.63 \pm 0.15 \mathrm{~mL}$ and $1.13 \pm$ $0.23 \mathrm{~mL}$. The mean semen volume significantly $(\mathrm{P}<0.05)$ decreased by post treatment week 2 in treated dogs, and thereafter the dogs became aspermic. The sperm motility of the dogs ranged between $73.75 \pm 5.5 \%$ and $85.00 \pm 4.7 \%$ (Table 2). It also decreased significantly $(\mathrm{P}<0.05) 2$ weeks following treatment (Table 1).

Similarly, the percentage live sperm of the dogs ranged between $77.50 \pm 6.0 \%$ and $91.25 \pm 6.0 \%$ (Table 2 ) and differed statis- tically significantly $(\mathrm{P}<0.05)$ by the second week after treatment with GnRH vaccine. The percentage abnormal sperm of the dogs ranged between $4.00 \pm 1.4 \%$ and $5.75 \pm 1.5 \%(\mathrm{P}<0.05$ by week 2$)$. Also, the mean sperm concentration of the dogs (ranging from $303.75 \pm 43.0$ to $385.00 \pm 55.0$ $\times 10^{6} \mathrm{sperm} / \mathrm{mL}$. The sperm concentration of the dogs also decreased significantly $(\mathrm{P}<$ $0.05)$ two weeks following treatment, and thereafter dogs became aspermic (Table 2).

\section{DISCUSSION}

The results of this study showed that the single subcutaneous injection of $\mathrm{GnRH}$

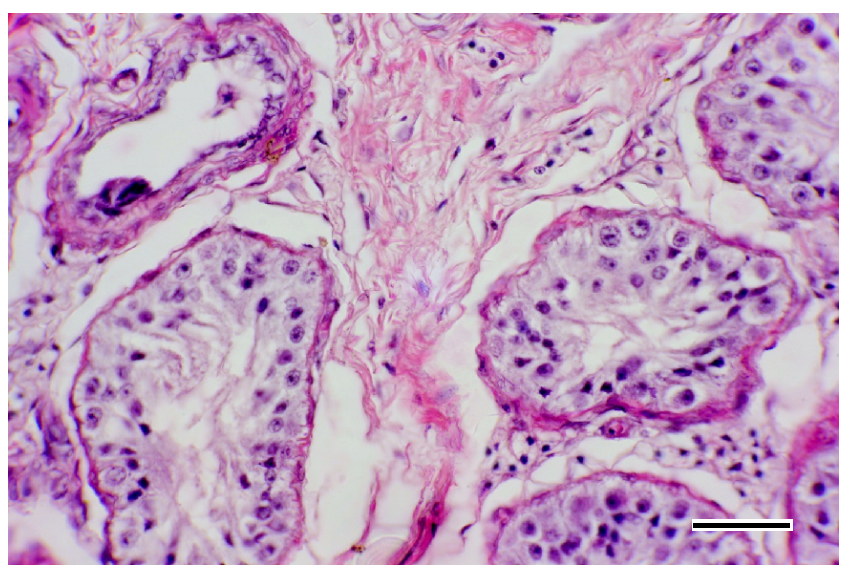

Fig. 3. Histopathology photomicrograph of a treated dog testis showing destroyed germ cells and narrowed seminiferous tubules. $\mathrm{H} \& \mathrm{E}$, bar $=100 \mu \mathrm{m}$.

Table 1. Semen volume and sperm motility of dogs (mean \pm SD) following treatment with single subcutaneous injection of GnRH vaccine (treated group; $n=5$ ) or normal saline (control group; $n=5$ )

\begin{tabular}{llccc}
\hline \multirow{2}{*}{$\begin{array}{l}\text { Time of } \\
\text { sampling }\end{array}$} & \multicolumn{2}{c}{ Sperm volume $(\mathrm{mL})$} & \multicolumn{2}{c}{ Sperm motility (\%) } \\
\cline { 2 - 5 } & Control group & Treated group & Control group & Treated group \\
\hline Week 0 & $0.68 \pm 0.15$ & $0.63 \pm 0.15$ & $73.75 \pm 5.5$ & $80.0 \pm 5.0$ \\
Week 2 & $0.95 \pm 0.23$ & $0.28 \pm 0.14$ & $76.25 \pm 6.5$ & $41.5 \pm 5.7$ \\
Week 4 & $0.80 \pm 0.18$ & $0.0 \pm 0.0$ & $73.75 \pm 5.3$ & $0.0 \pm 0.0$ \\
Week 6 & $0.90 \pm 0.15$ & $0.0 \pm 0.0$ & $75.00 \pm 6.0$ & $0.0 \pm 0.0$ \\
Week 8 & $1.13 \pm 0.23$ & $0.0 \pm 0.0$ & $77.00 \pm 5.6$ & $0.0 \pm 0.0$ \\
Week 10 & $0.73 \pm 0.14$ & $0.0 \pm 0.0$ & $77.50 \pm 6.0$ & $0.0 \pm 0.0$ \\
Week 12 & $1.08 \pm 0.25$ & $0.0 \pm 0.0$ & $82.00 \pm 5.3$ & $0.0 \pm 0.0$ \\
\hline
\end{tabular}


Table 2. Percentage live sperm, abnormal sperm and sperm concentration of dogs (mean \pm SD) following treatment with single subcutaneous injection of $\mathrm{GnRH}$ vaccine (treated group; $n=5$ ) or normal saline (control group; $n=5$ )

\begin{tabular}{lcccccc}
\hline \multirow{2}{*}{$\begin{array}{l}\text { Time of } \\
\text { sampling }\end{array}$} & \multicolumn{2}{c}{$\begin{array}{c}\text { Percentage live } \\
\text { sperm (\%) }\end{array}$} & \multicolumn{2}{c}{$\begin{array}{c}\text { Percentage sperm ab- } \\
\text { normality }(\%)\end{array}$} & \multicolumn{2}{c}{$\begin{array}{c}\text { Sperm concentration } \\
\left(\times 10^{6} \text { sperm } / \mathrm{mL}\right)\end{array}$} \\
\cline { 2 - 7 } & $\begin{array}{c}\text { Control } \\
\text { group }\end{array}$ & $\begin{array}{c}\text { Treated } \\
\text { group }\end{array}$ & $\begin{array}{c}\text { Control } \\
\text { group }\end{array}$ & $\begin{array}{c}\text { Treated } \\
\text { group }\end{array}$ & $\begin{array}{c}\text { Control } \\
\text { group }\end{array}$ & $\begin{array}{c}\text { Treated } \\
\text { group }\end{array}$ \\
\hline Week 0 & $83.50 \pm 7.5$ & $88.2 \pm 7.0$ & $5.75 \pm 1.5$ & $4.5 \pm 1.5$ & $410.0 \pm 37.0$ & $484.2 \pm 45.0$ \\
Week 2 & $86.50 \pm 6.5$ & $41.5 \pm 5.7$ & $5.75 \pm 1.3$ & $2.5 \pm 1.2$ & $368.7 \pm 53.0$ & $248.0 \pm 43.0$ \\
Week 4 & $85.00 \pm 7.4$ & $0.0 \pm 0.0$ & $4.00 \pm 1.5$ & $0.0 \pm 0.0$ & $385.0 \pm 55.0$ & $0.0 \pm 0.0$ \\
Week 6 & $77.50 \pm 6.0$ & $0.0 \pm 0.0$ & $5.50 \pm 2.0$ & $0.0 \pm 0.0$ & $384.0 \pm 46.0$ & $0.0 \pm 0.0$ \\
Week 8 & $88.00 \pm 7.8$ & $0.0 \pm 0.0$ & $4.00 \pm 1.4$ & $0.0 \pm 0.0$ & $303.7 \pm 43.0$ & $0.0 \pm 0.0$ \\
Week 10 & $91.25 \pm 6.0$ & $0.0 \pm 0.0$ & $4.00 \pm 1.5$ & $0.0 \pm 0.0$ & $340.0 \pm 60.0$ & $0.0 \pm 0.0$ \\
Week 12 & $90.00 \pm 7.3$ & $0.0 \pm 0.0$ & $4.50 \pm 1.3$ & $0.0 \pm 0.0$ & $335.0 \pm 53.0$ & $0.0 \pm 0.0$ \\
\hline
\end{tabular}

vaccine in dogs resulted into destruction of the germinal epithelium of the seminiferous tubules of the testes with concomitant decrease in the size of the testis and quality of the ejaculate. This effect occurred as early as two weeks following injection with the dogs becoming aspermic thereafter. Also, the effect lasted for up to 16 weeks after the administration of the vaccine.

Improvac is a synthetic, incomplete analogue of natural gonadotropin releasing hormone which is covalently linked to a carrier protein. The process of the conjugation prevents the hormone from binding to pituitary gonadotropin releasing hormone receptors thus completely eliminating any potential for hormonal activity. Although the vaccine is approved for use in the pigs for immunisation against boar taints (Bilskis et al., 2012), its use in this study did not produce any negative adverse reactions in the dogs. This confirmed the results of other authors that no detectable adverse reactions were elicited by the administration of Improvac (Zamaratskaia et al., 2008) and that the vaccine can be employed for castration in dogs.

In this study, decrease in both the scrotal circumference and testicular size were observed in the treated dogs when compared with the control dogs. In addition to this, there were disruptions of the germinal epithelium of the seminiferous tubules with loss of severe reduction of spermatids in the treated dogs. The disruption in normal spermatogenesis evidently led to the progressive drop in the ejaculate parameters of the dogs until they became aspermic. These changes suggest that the vaccine is a potent sterilisation agent in the dogs. It can be inferred that a single injection of the vaccine was able to induce infertility in the dogs or up to 16 weeks.

Sperm motility is an important characteristic in semen assessment. Spermatozoa gain motility during ejaculation as $\mathrm{pH}$ and bicarbonate concentration increases during mixing of sperm and seminal plasma (Vyt et al., 2004). The motility of the spermatozoa in the present study decreased progressively until the dogs became aspermic when compared to the control groups. This is contrary to the findings in pigs (Bilskis et al., 2012) and may be related to the inability of the dogs to produce seminal plasma fluid. Also, the total percentage of abnormal spermatozoa in the ejaculate was higher than that of the control dogs. This result was expected 
because vaccination indirectly locks the release of FSH which is required for normal spermatogenesis.

The advantage of the GnRH vaccine will be its virtual lack of any adverse effects and the ability to suppress semen production as early as two weeks following administration. This appears to be an advantage over the use of GnRH agonists in which the onset of sterility takes much longer time. In addition, the relatively cheap cost provides an additional advantage over the expensive GnRH agonist. The vaccine can be incorporated into the routine immunisation plans for dogs and thus be very useful in developing countries where there surgical facilities lack.

In conclusion, administration of single injection of GnRH vaccine to dogs resulted in decrease in the size of the testes and destruction of the germinal epithelium of the seminiferous tubules with resultant decrease in the ejaculate parameters until the dogs became azoospermic. This result showed that Improvac can be used as GnRH vaccine source for immunocastration in dogs. However, this is a preliminary study on the efficacy of Improvac as an immunosterilant vaccine in dogs, and it is yet to be determined how long it will take before reappearance of semen in immunised dogs. Therefore, further studies are necessary to determine the duration of spermatogenesis supprenssion in dogs after single administration of the vaccine.

\section{REFERENCES}

Bartlett, P. C., A. Bartlett, S. Walshaw \& S. Halstead, 2005. Rate of euthanasia and adoption for dogs and cats in Michigan Animal Shelters. Journal of Applied Animal Welfare Science, 8, 97-104.

Bilskis, R., N. Sutkeviciene, V. Riskeviciene, A. Januskauskas \& H. Zilinskas, 2012. Effect of active immunization against $\mathrm{GnRH}$ on testosterone concentration, libido and sperm quality in mature AI boars. Acta Veterinaria Scandinavica, 54, 33-39.

Kustritz, M. V., 2007. Determining the optimal age for gonadectomy of dogs and cats. Journal of the American Veterinary Medical Association, 231, 1665-1675.

Kutzler, M. \& A. Wood, 2006. Non-surgical methods of contraception and sterilization. Theriogenology, 66, 514-525.

LaCroix, C. E., 2006. Evaluation of a single intra-testicular injection of zinc gluconate neutralized by Arginine $\left(\right.$ Neutersol $\left.^{\mathbb{B}}\right)$ as a chemical sterilant in sexually matured male. In: Proceedings of the International Symposium on Non-Surgical Contraceptive Meethods for Pet Population Control, pp. 1-7.

Levy, J. K., P. C. Crawford, L. D. Appel \& E. L. Clifford, 2008. Comparison of intratesticular injection of zinc gluconate versus surgical castration to sterilize male dogs. American Journal of Veterinary Research, 69, 140-143.

Lund, E. M., P. J. Armstrong, C. A. Kirk \& J. S. Klausner, 2006. Prevalence and risk factors for obesity in adult dogs from private US veterinary practices. International Journal of Applied Research in Veterinary Medicine, 4, 177-186.

McNeil, J. \& E. Constandy, 2006. Addressing the problem of pet overpopulation: the experience of New Hanover County Animal Control Services. Journal of Public Health Management Practice, 12, 452-455.

Oliveira, E. C. S., M. R. Moura, V. A. Silva, C. A. Peixoto \& K. L. A. Saraiva, 2007. Intra-testicular injection of a zinc-based solution as a contraceptive for dogs, Theriogenology, 68, 137-145.

Soto, F. R., F. Ferreira, S. R. Pinheiro, N. Fernanda, R. R. Marcia, S. Osana \& A. Marcos, 2005. Adoption of shelter dogs in a Brazilian community: assessing the caretaker profile. Journal of Applied Animal Welfare Sciences, 8, 105-116.

Thompson, D. L., 2000. Immunization against $\mathrm{GnRH}$ in male species (comparative as- 
pects). Animal Reproduction Science, 60, 459-469.

Vyt, P., D. Maes, E. Rijsselaere, E. Dejonckheere, F. Castryck \& A. Van Soom, 2004. Motility assessment of porcine spermatozoa: A comparison of methods. Reproduction in Domestic Animals, 39, 447-453.

Walker, J., S. Ghosh \& J. Pagnon, 2007. Totally synthetic peptide based immunocontraceptive vaccines show activity in dogs of different breeds. Vaccine, 25, 71117119

Wiebe, V. J. \& J. P. Howard, 2009. Pharmacological advances in canine and feline reproduction. Topics in Companion Animal Medicine, 24, 71-99.

Zamatarskaia, G., H. K. Andersson, G. Chen, K. Andersson, A. Mades \& K. Lundstrom, 2006. Effect of a gonadotropin releasing hormone vaccine (Improvac TM) on steroid hormones, boar taint compounds and performance in entire male pigs. Reproduction in Domestic Animals, 43, 351-359.

Paper received 14.01.2014; accepted for publication 25.04.2014

\section{Correspondence:}

Dr Temitope Ajadi

Department of Veterinary Public Health and Reproduction,

Federal University of Agriculture, Abeokuta, PMB 2240, Alabata Road, Abeokuta, Ogun State, Nigeria tel: 234-806-956-0868

e-mail: ayisat_ajadi@yahoo.com 